Bài báo khoa hoc

\title{
Nghiên cứu phương pháp đánh giá rủi ro do xâm nhập mặn vùng đồng bằng ven biển Nam Định và Thái Bình
}

\author{
Nguyễn Văn Đào ${ }^{1}$, Vũ Thanh Tú ${ }^{2}$ Trần Hồng Thái ${ }^{3}$, Nguyễn Mai Đăng ${ }^{2,4^{*}}$ \\ ${ }^{1}$ Liên đoàn khảo sát khí tượng thuỷ văn, Tổng cục Khí tượng Thuỷ văn; \\ daotvmt@gmail.com \\ ${ }^{2}$ Khoa Kỹ thuật tài nguyên nước, Trường Đại học Thuỷ lợi; vutu@tlu.edu.vn \\ ${ }^{3}$ Tổng cục Khí tượng Thuỷ văn; tranthai.vkttv@gmail.com \\ ${ }^{4}$ Trung tâm Đào tạo Quốc tế, Trường Đại học Thuỷ lợi; dang@tlu.edu.vn \\ *Tác giả liên hệ: dang@tlu.edu.vn; Tel.: +84-989551699
}

Ban Biên tập nhận bài: 12/8/2021; Ngày phản biện xong: 29/9/2021; Ngày đăng bài: $25 / 12 / 2021$

Tóm tắt: Xâm nhập mặn $(\mathrm{XNM})$ thường xuyên có thể gây ra những tác động đến các hoạt động phát triển kinh tế-xã hội cho một vùng, khu vực. Để làm rõ những tác động do XNM đến vùng ven biển tỉnh Nam Định và Thái Bình, nghiên cứu này đã tiến hành xây dựng bộ chỉ số phân tích tính dễ bị tổn thương (TDBTT) từ đó đánh giá rủi ro (RR) và phân cấp tác động. Bộ chỉ số đánh giá TDBTT gồm 27 biến có trọng số, được lựa chọn nhằm phân tích về tính nhạy, độ phơi bày và khả năng ứng phó cho 243 xã trong vùng nghiên cứu. Các phương pháp điều tra, phỏng vấn, thống kê được áp dụng để xác định giá trị các biến và chuẩn hóa. Kết quả cho thấy số xã bị ảnh hưởng trong nhóm kịch bản $(\mathrm{KB})$ tần suất triều từ 125-149, nhóm KB nước biển dâng (NBD) từ 99-111, trong đó hơn $80 \%$ số xã của tỉnh Nam Định bị tác động. Nghiên cứu đã tính toán cho 5 cấp tổn thương và RR, tuy nhiên đa phần các xã đều chịu tổn thương và RR ở cấp độ $1-2$. Kết quả nghiên cứu đã cho thấy, mặc dù tại một số xã mức độ hiểm họa khá cao, tuy nhiên với khả năng ứng phó tốt, thì mức độ tổn thương và rủi ro cũng có thể rất thấp hoặc có thể không xảy ra.

Từ khóa: Xâm nhập mặn; Bộ chỉ số; Tính dễ bị tổn thương; Rủi ro; Nước biển dâng.

\section{Mở đầu}

Các khu vực có vùng cửa sông giáp biển như đồng bằng sông Hồng-Thái Bình ở nước ta luôn phải đối mặt với hiện tượng XNM, đó là quy luật hoàn toàn tự nhiên không thể tránh khỏi. Không giống như các hiểm họa khác (bão, lũ, ngập lụt v.v..), XNM có thể gây ra các thiệt hại nhỏ nhưng trong thời gian dài, nếu không có các giải pháp ứng phó kịp thời thì tổng thiệt hại có thể lớn hơn so với các loại hình thiên tai khác [1-4]. Đánh giá rủi ro (ĐGRR) có thể được xác định dựa trên TDBTT và mức độ hiểm họa. TDBTT được xác định dựa trên mức độ phơi bày, tính nhạy và phục hồi, và khả năng ứng phó. Chính vì vậy, ĐGRR thiên tai có thể giúp xác định được một khu vực cụ thể có khả năng chịu RR cao hay thấp. Từ đó, các giải pháp cụ thể sẽ được đưa ra nhằm khắc phục những điểm còn hạn chế trong công tác phòng chống thiên tai và tập trung hỗ trợ cho các vùng chịu RR cao, tránh được việc đưa ra các giải pháp không phù hợp hoặc ở các vùng không phải là "điểm nóng" [5-8].

Trong số các nghiên cứu đã được công bố trên các tạp chí của nước ngoài về lập bản đồ các vùng bị tổn thương nói chung, chỉ có $9 \%$ công trình nghiên cứu xác định TDBTT thông qua các phiếu điều tra, số còn lại thì dựa vào các báo cáo thống kê tổng hợp [6]. Ở Việt Nam hiện nay cũng có một số nghiên cứu đánh giá ảnh hưởng của độ mặn dựa trên các phương 
pháp thí nghiệm cho một số đối tượng cây trồng như lúa, hoa mầu [10-11,13]. Bên cạnh đó các hoạt động nuôi trồng thủy sản nước cũng bị ảnh hưởng do sốc độ mặn [12, 14-17]. Tuy nhiên, các nghiên cứu đó mới chỉ dừng lại ở mức đánh giá sự tăng giảm độ mặn ảnh hưởng đến các giống loài riêng lẻ mà chưa có đánh giá tổng hợp tác động của XNM đến hoạt động phát triển kinh tế-xã hội ở địa phương. Để khắc phục hạn chế này, một số nghiên cứu cũng đã dựa trên các số liệu thống kê và các bộ chỉ số để đánh giá TDBTT của XNM đến một số huyện ven biển tỉnh Nam Định và Thái Bình [18-19]. Tuy nhiên, các bộ chỉ số này còn chưa xét tới tầm quan trọng của các chỉ số (trọng số) và mới đánh giá TDBTT cho KB cụ thể và trong phạm vi diện tích khá lớn (cấp huyện), trong khi đó diễn biến XNM có thể rất khác nhau giữa các xã. Thêm vào đó điều kiện kinh tế-xã hội cũng như năng lực và sự thích ứng với XNM của các xã cũng khác nhau, dẫn tới cấp độ dễ bị tổn thương và $R R$ cũng có thể khác nhau. Vì vậy, việc xác định TDBTT và ĐGRR trên phạm vi diện tích càng nhỏ thì càng đem lại hiệu quả cao trong công tác quản lý $R R$ trên toàn vùng nói chung. Kế thừa kết quả phân tích hiểm họa do XNM theo các KB tần suất triều và NBD trong bối cảnh biến đổi khí hậu đã thực hiện cho 243 xã thuộc 8 huyện ven biển tỉnh Nam Định và Thái Bình [20]. Nghiên cứu này tiếp tục xây dựng bộ chỉ số nhằm phân tích TDBTT và ĐGRR do XNM cho các xã thuộc vùng ven biển Nam Định và Thái Bình tương ứng với các $\mathrm{KB}$ hiểm họa do $\mathrm{XNM}$ diễn ra trên khu vực.

Để xác định TDBTT và ĐGRR do XNM, nghiên cứu tiếp cận theo các trình tự như sau: (1) Thu thập, phân tích đánh giá hiện trạng XNM, những đối tượng chịu ảnh hưởng và mức độ thiệt hại trong những năm gần đây; (2) Đề xuất các chỉ số nhằm đánh giá TDBTT bao gồm các chỉ số về độ nhạy, mức độ phơi bày và khả năng ứng phó, có xét tới tầm quan trọng của các chỉ số (trọng số); (3) Phân cấp tính dễ bị tổn thương theo các cấp từ thấp đến cao theo các KB XNM do triều cường và NBD dưới tác động của biến đổi khí hậu; (4) ĐGRR do XNM dựa trên kết quả phân tích TDBTT và hiểm họa. Các phương pháp được áp dụng bao gồm: phương pháp điều tra, phỏng vấn, phương pháp phân tích thống kê, phương pháp phân tích hệ thống phân cấp AHP (Analysis Hierarchy Process), phương pháp phân tích bản đồ và kỹ thuật GIS.

\section{Phương pháp nghiên cứu và thu thập số liệu}

\subsection{Tình hình XNM và công tác phòng chống thiên tai khu vục nghiên cưu}

\subsubsection{Tình hình XNM}

Vùng đồng bằng châu thổ sông Hồng-Thái Bình có diện tích ước tính khoảng 17.000 $\mathrm{km}^{2}$. Với $58,4 \%$ diện tích đồng bằng sông Hồng có cao trình thấp hơn $2 \mathrm{~m}$, nếu không có hệ thống đê biển và đê vùng cửa sông thì vùng diện tích này hoàn toàn bị ảnh hưởng bởi thuỷ triều do cao trình vùng mặt đất bãi sông ngoài đê thường cao hơn cao trình mặt đất trong dòng chính từ 3-5 m. Hệ thống sông Hồng-Thái Bình đổ ra biển bằng 9 cửa sông, gồm: Cửa Đáy, Ninh Cơ, Ba Lạt, Trà Lý, Thái Bình, Văn Úc, Lạch Tray, Cấm và Bạch Đằng. Ở vịnh Bắc Bộ có chế độ nhật triều, có độ lớn thuỷ triều trong một ngày thuộc loại lớn nhất ở Việt Nam. Một ngày có một đỉnh triều và một chân triều ( $\Delta \mathrm{H}$ max đạt tới 3,5-4,0 $\mathrm{m}$ ). Thời gian triều lên khoảng 11 giờ và triều xuống khoảng 13 giờ. Do vậy, sóng đỉnh triều có thể tiến vào sâu trong lục địa lên tới hơn $100 \mathrm{~km}$, tùy thuộc vào mùa và ở các sông khác nhau.

Qua số liệu thực đo, sự diễn biến của độ mặn trong sông biến đổi theo các mùa, nhỏ về mùa lũ $(\mathrm{VI}-\mathrm{IX})$, lớn về mùa cạn $(\mathrm{X}-\mathrm{IV})$, tuỳ theo lượng nước ngọt từ thượng lưu đổ về và độ lớn của thủy triều, của lưới sông. Nhìn chung, độ mặn lớn nhất thường xuất hiện vào tháng I và II. Độ mặn có xu hướng tăng ở dòng chính sông Hồng và giảm phía sông Thái Bình. Tính trung bình nhiều năm từ chuỗi số liệu đo đạc, chiều dài xâm nhập mặn 1\%o xa nhất trên sông Thái Bình 13-49 km (tuỳ từng phân lưu), Ninh Cơ 36 km, Trà Lý 51 km, Đáy 41 km và sông Hồng 14-33 km. 


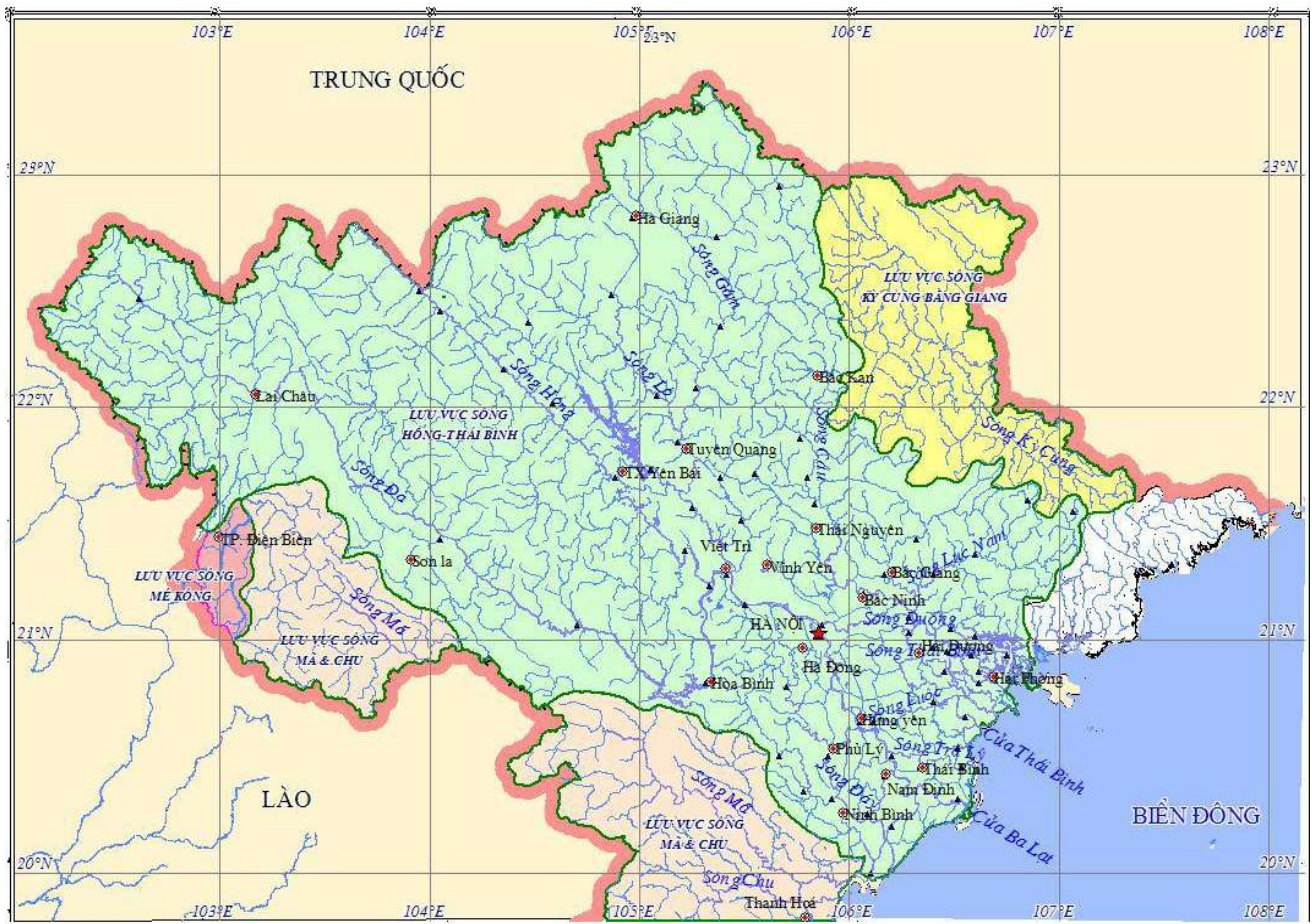

Hình 1. Lưu vực sông Hồng-Thái Bình thuộc lãnh thổ Việt Nam [20].

\subsubsection{Công tác phòng chống thiên tai}

Nhằm chủ động phòng chống và ứng phó kịp thời đạt hiệu quả, giảm thiểu thiệt hại do thiên tai gây ra, Ủy ban nhân dân tỉnh Nam Định và Thái Bình hàng năm đã thực hiện các hội nghị tổng kết công tác phòng chống thiên tai và tìm kiếm cứu nạn nhằm đánh giá những điểm đã đạt được, những tồn tại và nên kế hoạch cho năm sau. Cùng với đó là kế hoạch phòng, chống thiên tai và tìm kiếm cứu nạn cho các giai đoạn 5 năm, và có rà soát theo từng năm để phù hợp với bối cảnh mới ở từng địa phương. Nhìn chung các kế hoạch này đều được xây dựng với các mục tiêu: (1) Đảm bảo an toàn tuyệt đối về người, giảm thiểu thiệt hại về tài sản của nhà nước và nhân dân; (2) Bảo vệ an toàn cho các tuyến đê, kè, cống, các công trình, vật kiến trúc, đặc biệt là các tuyến đê trọng điểm đã được xác định qua công tác kiểm tra, đánh giá chất lượng trước mùa lũ bão; (3) Bảo vệ sản xuất và môi trường sinh thái; (4) Nâng cao năng lực xử lý tình huống, sự cố, chỉ huy, điều hành tại chỗ để ứng phó thiên tai đạt hiệu quả của các cấp, các ngành; (5) Nâng cao nhận thức của người dân về quản lý RR thiên tai dựa vào cộng đồng để phát huy ý thức tự giác, chủ động phòng, tránh thiên tai của toàn dân trên địa bàn tỉnh [21-22].

Tuy nhiên, trong công tác thực hiện hàng năm, cũng có một số điểm còn hạn chế như: (1) Sự phối hợp của các địa phương trong việc triển khai công tác chưa chặt chẽ, dẫn đến các văn bản còn chậm trễ; (2) Việc ứng dụng các mô hình, phần mềm phục vụ cho công tác dự báo còn rất hạn chế do cơ sở vật chất chưa đảm bảo, mạng lưới trạm còn thưa chưa đáp ứng về dự báo điểm trong toàn tỉnh; (3) Công tác quản lý khai thác công trình thủy lợi gặp nhiều khó khăn do còn nhiểu công trình xây dựng từ lâu, đã xuống cấp đặc biệt các công trình đầu mối; (4) Công tác chuẩn bị vật tư dự trữ theo phương châm "4 tại chỗ" của một số địa phương chưa đủ số lượng, chủng loại theo chỉ tiêu giao; (5) Công tác thống kê, báo cáo về tình hình thiệt hại của các địa phương còn chậm và thiếu chính xác, chưa kịp thời nhất là thiệt hại về sản xuất gây khó khăn cho việc tổng hợp thiệt hại; (6) Công tác tuyên truyền, cập nhật thông tin về thiên tai có nơi, có lúc còn hình thức, chậm và chưa đạt yêu cầu. Nhận thức về phòng tránh, giảm nhẹ thiên tai, khả năng tự phòng tránh, tự ứng cứu của nhân dân một số địa phương còn hạn chế. 


\subsection{Xây dưng bộ chỉ số TDBTT và đánh giá RR do xâm nhập mặn}

\subsubsection{Lựa chọn các chỉ số đánh giá}

Việc lựa chọn các chỉ số đánh giá TDBTT do XNM phải dựa trên: (1) Các báo cáo thống kê về thiệt hại do XNM gây ra để làm rõ các đối tượng chịu tác động; (2) Khả năng thu thập số liệu từ các nguồn thông tin có độ tin cậy cao; (3) Chuyên gia cho vấn đề cần được quan tâm. Bởi vậy, thông qua phân tích các kết quả thu được từ khảo sát thực địa, phỏng vấn chuyên gia, các chỉ số đánh giá TDBTT do XNM đã được lựa chọn và phân tích xác định trọng số theo AHP thể hiển trong Bảng 1 , bao gồm các thành phần:

Độ nhạy: biểu thị các tính chất về xã hội và kinh tế của khu vực. Trong đó các biến liên quan đến đặc điểm nhân khẩu và sinh kế được sử dụng để phản ánh tính chất kinh tế xã hội của vùng nghiên cứu.

Độ phơi bày: biểu thị cho đối tượng trong khu vực khi tiếp xúc trực tiếp với hiểm họa nếu xảy ra. Đối với loại hình XNM, các đối tượng chịu ảnh hưởng trực tiếp hoặc gián tiếp có thể xét tới đó là các hoạt động sản xuất nông nghiệp và người lao động trong lĩnh vực nông nghiệp. XNM có những tác động trực tiếp đến các hoạt động nông nghiệp bao gồm: ảnh hưởng đến sản lượng lúa, hoa mầu, cây ăn quả, thủy sản và các hoạt động chăn nuôi gia súc, gia cầm. Do sự giảm sản lượng, thậm chí là mất trắng khi cây trồng/vật nuôi bị ảnh hưởng của XNM, người lao động trong lĩnh vực nông nghiệp cũng bị ảnh hưởng tới thu nhập cá nhân, gia đình nói riêng và phát triển kinh tế-xã hội của địa phương nói chung.

Khả năng ứng phó: biểu thị cho khả năng chống chịu, ứng phó và phục hồi trước và sau những tác động của hiểm họa.

\subsubsection{Cơ sở định lượng các biến trong bộ chỉ số đánh giá TDBTT}

Trong nhóm các biến đã thể hiện trong Bảng 1 , các chỉ số về nhân khẩu và sinh kế ( $\mathrm{S} 1-$ S7), số người lao động trong lĩnh vực nông nghiệp (E2), các thu nhập bình quân (A1-A2), tỷ lệ cấp nước hợp vệ sinh $(\mathrm{A} 3)$ có thể xác định được từ tài liệu Niên giám thống kê của các huyện trong phạm vi nghiên cứu. Nhóm các chỉ số về sản lượng nông nghiệp bị ảnh hưởng bởi XNM (E3-E8) có thể dựa trên cơ sở tài liệu Niên giám thống kê và kế thừa các nghiên cứu về tác động của độ mặn tới sự sinh trưởng và phát triển của các loại cây trồng và vật nuôi được phân tích ở các phần sau đây.

Đối với cây lúa: nhìn chung các nghiên cứu đều nhận định rằng sau thời gian dài tiếp xúc với mặn, sự phát triển của cây lúa bị giảm. Mặn giảm sức trương của mô tế bào, hạn chế trực tiếp sinh trưởng và phát triển của cây và dẫn đến giảm năng suất hạt. Các kết quả nghiên cứu cũng cho thấy khi độ mặn càng tăng thì năng suất càng giảm [23-26]. Trên cơ sở các nghiên cứu đánh giá ảnh hưởng của độ mặn tới một số giống lúa ở Việt Nam đã được thực hiện $[9,25-27]$, nghiên cứu này ước tính mức giảm năng suất cho các giống lúa được trồng tại tỉnh Nam Định và Thái Bình thể hiện trong Bảng 2.

Bảng 1. Bộ chỉ số đánh giá TDBTT do XNM.

\begin{tabular}{|c|c|c|c|c|c|}
\hline Thành phần & Chỉ số & Biến & Ký hiệu & Đơn vị & Trọng số \\
\hline \multirow{7}{*}{ Tính nhạy } & \multirow{7}{*}{$\begin{array}{l}\text { Nhân khẩu } \\
\text { và sinh kế }\end{array}$} & Dân số trung bình & $\mathrm{S} 1$ & Người & 0,05 \\
\hline & & Mật độ dân số & S2 & Người/km² & 0,16 \\
\hline & & $\begin{array}{l}\text { Số người dưới } 15 \text { tuổi và trên } 60 \\
\text { tuổi }\end{array}$ & S3 & Người & 0,12 \\
\hline & & Tỷ lệ Nam & S4 & $\%$ & 0,27 \\
\hline & & Trình độ văn hóa (cao nhất) & S5 & & 0,16 \\
\hline & & Tỷ lệ hộ nghèo và cận nghèo & S6 & $\%$ & 0,07 \\
\hline & & Số lao động phi nông nghiệp & S7 & Người & 0,16 \\
\hline \multirow{3}{*}{ Độ phơi bày } & Độ mặn & Độ mặn lớn nhất & E1 & PSU & 0,26 \\
\hline & \multirow[t]{2}{*}{ Người } & $\begin{array}{l}\text { Số người lao động trong lĩnh } \\
\text { vực Nông nghiệp bị ảnh hưởng }\end{array}$ & $\mathrm{E} 2$ & Người & 0,28 \\
\hline & & Lúa bị ảnh hưởng & E3 & Sản lượng & 0,08 \\
\hline
\end{tabular}




\begin{tabular}{|c|c|c|c|c|c|}
\hline Thành phần & Chỉ số & Biến & Ký hiệu & Đơn vị & Trọng số \\
\hline \multirow{17}{*}{$\begin{array}{l}\text { Khả năng } \\
\text { chống chịu }\end{array}$} & \multirow{6}{*}{$\begin{array}{l}\text { Nông } \\
\text { nghiệp }\end{array}$} & Hoa mầu bị ảnh hưởng & E4 & & 0,05 \\
\hline & & Cây ăn quả bị ảnh hưởng & E5 & & 0,06 \\
\hline & & $\begin{array}{l}\text { Thủy sản nước ngọt bị ảnh } \\
\text { hướng }\end{array}$ & E6 & & 0,1 \\
\hline & & Thủy sản nước lợ bị ảnh hưởng & E7 & & 0,08 \\
\hline & & Gia súc, gia cầm bị ảnh hưởng & E8 & Số lượng & 0,08 \\
\hline & & $\begin{array}{l}\text { Thu nhập từ nguôn lao động phi } \\
\text { nông nghiệp }\end{array}$ & A1 & Triệu đồng & 0,03 \\
\hline & \multirow{11}{*}{$\begin{array}{l}\text { Úng phó, } \\
\text { khắc phục }\end{array}$} & Thu nhập bình quân đầu người & A2 & Triệu đồng & 0,04 \\
\hline & & \multirow{3}{*}{$\begin{array}{l}\text { Tỷ lệ cấp nước hợp vệ sinh } \\
\text { Tỷ lẹ̣ cơ sở hạ tâng được tu sửa } \\
\text { thường xuyên } \\
\text { Tỷ lệ hệ thống tưới/ tiêu được bê } \\
\text { tông hóa }\end{array}$} & A3 & $\%$ & 0,13 \\
\hline & & & A4 & & 0,15 \\
\hline & & & A5 & & 0,12 \\
\hline & & Cấp nước tưới và đẩy mặn & A6 & & 0,11 \\
\hline & & $\begin{array}{l}\text { Tập huân ứng phó xâm nhập } \\
\text { mặn }\end{array}$ & A7 & & 0,07 \\
\hline & & Dự báo, cảnh báo & A8 & & 0,09 \\
\hline & & Nhận thức về XNM và NBD & A9 & & 0,05 \\
\hline & & Bản đồ phân vùng XNM & A10 & & 0,05 \\
\hline & & $\begin{array}{l}\text { Giải pháp, Phương án ứng phó } \\
\text { đối với XNM }\end{array}$ & A11 & & 0,1 \\
\hline & & Nguồn nhân lực, vật lực & A12 & & 0,05 \\
\hline
\end{tabular}

Bảng 2. Mức giảm năng suất ước tính đối với các giống lúa trồng tại vùng nghiên cứu.

\begin{tabular}{ccc}
\hline $\begin{array}{c}\text { Độ mặn } \\
\text { (dS/m) }\end{array}$ & $\begin{array}{c}\text { Độ mặn } \\
\text { (psu) }\end{array}$ & $\begin{array}{c}\text { Mức giảm năng suất } \\
\text { (\%) }\end{array}$ \\
\hline 3 & 1,9 & 0 \\
4 & 2,6 & 5,58 \\
5 & 3,2 & 9,73 \\
6 & 3,8 & 15,15 \\
8 & 5,1 & 26,16 \\
10 & 6,4 & 36,20 \\
\hline
\end{tabular}

Hoa mầu và cây ăn quả: cũng như lúa, các loại cây trồng khác cũng chịu ảnh hưởng lớn của mặn trong các giai đoạn sinh trưởng như trì hoãn việc nảy mầm, thay đổi hình thái, cấu trúc cây, sự cân bằng dinh dưỡng và hạn chế năng suất. Theo các nghiên cứu [13, 28-31] nói chung mức chịu mặn của các hoa mầu dao động trong khoảng từ 1-3\%o, ở trên mức $3 \%$, năng suất cây trồng giảm khoảng $40-50 \%$ và ở mức trên $6 \%$ o thì mức giảm đến hơn $90 \%$ và có thể chết cây. Đối với nhóm cây ăn quả mức chịu mặn cũng ở mức dưới $1 \%$.

Ảnh hưởng của độ mặn đến vấn đề tiêu hóa và hô hấp của các loài thủy sản cũng đã được nhiều tác giả nghiên cứu và cho thấy mức độ thay đổi các phản ứng khác nhau tùy thuộc vào loài, giai đoạn phát triển [7-8]. Đối với thủy sản nước lợ, thì điều kiện phát triển tốt nhất trong khoảng từ 10-15\%. Trong điều kiện bị sốc độ mặn theo hướng ngọt hóa, tức là độ mặn ở mức 5\%, thì tỷ lệ sống chỉ chiếm khoảng 45\%. Nếu độ mặn lớn hơn ở mức $20 \%$ o thì tỷ lệ sống khoảng trên $92 \%$ (đối với tôm) và nếu ở mức trên $25 \%$ thì tỷ lệ sống chỉ còn khoảng $57 \%$, trong khi đó có một số loài cá cũng chết hàng loạt [14-17, 32-37]. Đối với cá nước ngọt, môi trường lý tưởng là ở mức dưới $4 \%$, một số có thể chịu đến mức $10 \% \mathrm{o}$. Tỷ lệ sống giảm khoảng $22 \%, 32 \%$ và $49 \%$ tương ứng với các ngưỡng mặn $6 \%, 9 \%$ và $12 \% 0$ [38].

Về khả năng chịu mặn của gia súc gia cầm, theo Trung tâm Khuyến nông quốc gia, các loại gia súc gia cầm như: gà vịt chịu đựng mặn từ $1-2 \%$, heo dưới $4 \%$, trâu, bò và dê dưới $7 \%$, vịt biển từ $11-15 \%$. Gia súc non, đang mang thai và cho sữa chịu mặn kém hơn ở gia súc trưởng thành và gia súc nuôi thịt [39]. 
Các chỉ số về khả năng ứng phó và khắc phục (A4-A12) có thể thực hiện thông qua công tác điều tra thực địa và phỏng vấn cũng như các báo cáo công tác phòng chống thiên tai và tìm kiếm cứu nạn hàng năm tại địa phương. Ngoài câu hỏi định lượng trực tiểp giá trị các biến A4-A6, các biến A7-A12 được xác định thông qua các câu hỏi chi tiết hơn. Cụ thể về công tác tập huấn, nâng cao năng lực ứng phó XNM các câu hỏi bao gồm số người được tập huấn, số đợt tập huấn trong năm, nội dung tập huấn. Về công tác dự báo, cảnh báo các câu hỏi bao gồm thời gian dự báo, cảnh báo, độ tin cậy, cơ sở hạ tầng phục vụ công tác dự báo. Đánh giá nhận thức của địa phương về XNM các câu hỏi bao gồm công tác tuyên truyền, hoạt động tổng kết hàng năm, thống kê thiệt hại, công tác ứng phó; Về sử dụng các bản đồ phân vùng XNM phục vụ cho các kế hoạch ứng phó có kế thừa hoặc tự xây dựng các bản đồ phân vùng và phồ biến cho các đơn vị hay không. Về giải pháp, phương án ứng phó các câu hỏi bao gồm có xây dựng các KB XNM không, giải pháp cụ thể trong tình huống xảy ra, mức đầu tư cho các giải pháp. Về nguồn nhân lực và vật lực các câu hỏi bao gồm số nhân lực, vật tư, trang thiết bị, phương tiện và quỹ phòng chống thiên tai.

Trong các biến và tiêu chí lựa chọn, có những biến có thể xác định được bằng cách định lượng rõ ràng, nhưng một số biển chỉ có thể xác định bằng phương pháp định tính. Với các biến được xác định theo phương pháp định tính (A6-A12) khoảng giá trị được xác định nằm trong khoảng từ 0 (rất thấp) đến 5 (rất tốt). Cùng với đó, các biến có đơn vị tính khác nhau, để có thể thực hiện tính toán xác định các thành phần trong công thức xác định TDBTT dưới đây, cần phải thực hiện chuẩn hóa dữ liệu.

Từ các dữ liệu đầu vào phân tích, việc chuẩn hóa sẽ chuyển các giá trị này thành các giá trị nằm trong khoảng $0-1$, theo công thức (1).

$$
\begin{aligned}
& x_{i}=\frac{X_{i}-X_{\min }}{X_{\max }-X_{\min }} \text { nếu giá trị của biến càng cao khả năng gây tổn thương cao; } \\
& x_{i}=\frac{X_{\max }-X_{i}}{X_{\max }-X_{\min }} \quad \text { nếu giá trị của biến càng cao khả năng gây tổn thương thấp }
\end{aligned}
$$

Trong đó $\mathrm{x}_{\mathrm{i}}$ là giá trị được chuẩn hóa; $\mathrm{X}_{\mathrm{i}}$ là giá trị thực; $\mathrm{X}_{\max }$ là giá trị lớn nhất; $\mathrm{X}_{\min }$ là giá trị nhỏ nhất.

Tham khảo các nghiên cứu [40-42], TDBTT tại mỗi xã trong khu vực nghiên cứu được xác định theo công thức (2).

$$
V_{i}=\sum_{k=1}^{7} S_{k, i} * w_{k, i}+\sum_{h=1}^{8} E_{h, i} * w_{h, i}-\sum_{t=1}^{12} A_{t, i} * w_{t, i}
$$

Trong đó $\mathrm{S}_{\mathrm{k}, \mathrm{i}}$ là các biến thuộc tính nhạy; $\mathrm{E}_{\mathrm{h}, \mathrm{i}}$ là các biến thuộc độ phơi bày; $\mathrm{A}_{\mathrm{t}, \mathrm{i}}$ là các

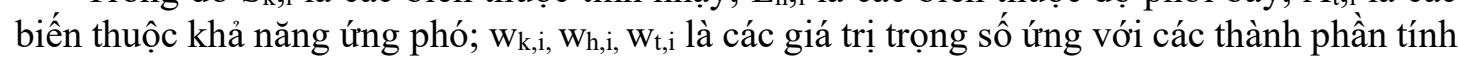
nhạy, độ phơi bày và khả năng ứng phó tại xã thứ (i) theo từng KB XNM.

Theo định nghĩa $\mathrm{RR}$ được xác định tại từng xã trong khu vực nghiên cứu theo công thức:

$$
\mathrm{R}_{\mathrm{i}}=\mathrm{H}_{\mathrm{i}} \times \mathrm{V}_{\mathrm{i}}
$$

Trong đó $\mathrm{H}_{\mathrm{i}}$ là khả năng xuất hiện hiểm họa, $\mathrm{V}_{\mathrm{i}}$ là tính dễ bị tổn thương tương ứng với KB XNM xác định từ công thức (2).

Tham khảo nghiên cứu [43], khi đó tổ hợp RR tại từng xã được xác định theo công thức (4).

$$
R_{i}=\frac{\sum_{j=1}^{m}\left[R_{i, j} \times w_{j}\right]}{\sum_{j=1}^{m} w_{j}}
$$

Trong đó $R_{i, j}$ là $R R$ tại xã thứ (i) ứng với $K B(j) ; w_{j}$ là trọng số của $K B(j)$ tương ứng với khả năng xuất hiện XNM; m là số KB tính toán.

Các KB tính toán cụ thể bao gồm: Đối với nhóm KB tần suất triều, quá trình lưu lượng tại các trạm biên trên được giả thiết là đồng nhất giữa các KB tính toán. Quá trình triều và mặn tại các trạm biên dưới là thay đổi theo $6 \mathrm{~KB}$ ứng với các tần suất xuất hiện: $\mathrm{P}=1 \%, 3 \%$, $5 \%, 10 \%, 20 \%$ và $25 \%$. Nhóm KB NBD: (1) thời kỳ nền; (2) RCP4.5 năm 2030; (3) RCP4.5 năm 2040; (4) RCP4.5 năm 2050; và (5) RCP8.5 năm 2050 [20]. 
Giá trị rủi ro $\mathrm{R}_{\mathrm{i}}$ nằm trong khoảng từ 0 (không có $\mathrm{RR}$ ) đến 1 ( $\mathrm{RR}$ rất cao), để phân cấp độ RR tại các xã, phân chia thành 5 cấp: $0-0,01$ : không RR, $0,01-0,2$ : RR rất thấp; $0,2-0,4$ : RR thấp; $0,4-0,6$ : RR trung bình; $0,6-0,8$ : RR cao và $0,8-1,0$ : RR rất cao.

\section{Kết quả và thảo luận}

\subsection{Kết quả tính toán các KB tần suất triều}

Theo kết quả tính toán TDBTT ứng với các KB tần suất triều được tổng hợp trong Bảng 3 và Bảng 4 nhận thấy đối với tỉnh Nam Định, tổng số xã chịu tổn thương do XNM dao động trong khoảng 92-108 xã trên tổng số 123 xã của vùng nghiên cứu, Trong khi đó, với 120 xã thuộc phạm vi nghiên cứu tại tỉnh Thái Bình, số xã bị tổn thương chỉ dao động trong khoảng 33-41 xã. Sự khác biệt lớn về số xã bị tổn thương giữa hai tỉnh xuất phát từ kết quả tính toán về cấp độ hiểm họa do XNM trong khu vực nghiên cứu [20] với khoảng $87 \%$ số xã thuộc tỉnh Nam Định chịu ảnh hưởng của độ mặn trên 4\%, trong khi đó trên phạm vi tỉnh Thái Bình chỉ có khoảng $26 \%$. Thêm vào đó, trên cơ sở đánh giá về các điều kiện kinh tế xã hội vùng nghiên cứu bao gồm nhân khẩu và sinh kế, sản lượng nông nghiệp có thể bị ảnh hưởng do XNM và khả năng ứng phó, khắc phục của địa phương cũng dẫn tới số xã bị tổn thương và cấp độ bị tổn thương do XNM trên địa bản tỉnh Thái Bình thấp hơn so với tỉnh Nam Định.

Cấp độ tổn thương cũng như RR được phân theo 5 cấp, tuy nhiên có thể nhận thấy đa phần các xã trên địa bàn 2 tỉnh đều chịu tổn thương ở cấp $1-2$, trong đó $75-85 \%$ các xã chịu tổn thương ở cấp 1 . Trong số các xã trên chỉ có xã Nghĩa Hải, huyện Nghĩa Hưng, tỉnh Nam Định chịu tổn thương và $R R$ ở cấp 3 .

Bảng 3. Số xã chịu tổn thương theo các KB tần suất triều và cấp RR trên phạm vi tỉnh Nam Định.

\begin{tabular}{|c|c|c|c|c|c|c|c|c|c|}
\hline \multirow[b]{2}{*}{ Cấp độ } & \multirow{2}{*}{$\begin{array}{c}\text { Khoảng giá } \\
\text { trị }\end{array}$} & \multicolumn{7}{|c|}{ Số xã chịu tổn thương (V) ứng với các tần suất } & \multirow{2}{*}{$\begin{array}{c}\text { Số xã } \\
\text { chịu } \\
\text { RR }\end{array}$} \\
\hline & & $\begin{array}{l}P= \\
1 \%\end{array}$ & $\begin{array}{l}P= \\
\mathbf{3} \%\end{array}$ & $\begin{array}{l}P= \\
5 \%\end{array}$ & $\begin{array}{c}P= \\
10 \%\end{array}$ & $\begin{array}{c}P= \\
15 \%\end{array}$ & $\begin{array}{c}P= \\
20 \%\end{array}$ & $\begin{array}{c}P= \\
25 \%\end{array}$ & \\
\hline 0 & $<0,01$ & 15 & 17 & 20 & 21 & 27 & 30 & 31 & 23 \\
\hline 1 & $0,01-0,2$ & 83 & 87 & 86 & 86 & 80 & 77 & 76 & 84 \\
\hline 2 & $0,2-0,4$ & 24 & 18 & 16 & 15 & 15 & 15 & 15 & 15 \\
\hline 3 & $0,4-0,6$ & 1 & 1 & 1 & 1 & 1 & 1 & 1 & 1 \\
\hline 4 & $0,6-0,8$ & 0 & 0 & 0 & 0 & 0 & 0 & 0 & 0 \\
\hline 5 & $>0,8$ & 0 & 0 & 0 & 0 & 0 & 0 & 0 & 0 \\
\hline \multicolumn{2}{|c|}{ Tổng số bị ảnh hưởng } & 108 & 106 & 103 & 102 & 96 & 93 & 92 & 100 \\
\hline \multicolumn{2}{|c|}{ Tổng số xã } & \multicolumn{8}{|c|}{123} \\
\hline
\end{tabular}

Bảng 4. Số xã chịu tổn thương theo các $\mathrm{KB}$ tần suất triều và cấp RR trên phạm vi tỉnh Thái Bình.

\begin{tabular}{|c|c|c|c|c|c|c|c|c|c|}
\hline \multirow[b]{2}{*}{ Cấp độ } & \multirow[b]{2}{*}{$\begin{array}{c}\text { Khoảng giá } \\
\text { trị }\end{array}$} & \multicolumn{7}{|c|}{ Số xã bi tổn thương (V) ứng với các tần suất } & \multirow{2}{*}{$\begin{array}{c}\text { Số xã } \\
\text { chịu } \\
\text { RR }\end{array}$} \\
\hline & & $\begin{array}{l}P= \\
1 \%\end{array}$ & $\begin{array}{l}P= \\
3 \%\end{array}$ & $\begin{array}{l}P= \\
5 \%\end{array}$ & $\begin{array}{c}P= \\
10 \%\end{array}$ & $\begin{array}{c}P= \\
15 \%\end{array}$ & $\begin{array}{c}P= \\
20 \%\end{array}$ & $\begin{array}{c}P= \\
25 \%\end{array}$ & \\
\hline 0 & $<0,01$ & 79 & 80 & 80 & 85 & 87 & 87 & 87 & 87 \\
\hline 1 & $0,01-0,2$ & 31 & 30 & 30 & 27 & 26 & 28 & 28 & 27 \\
\hline 2 & $0,2-0,4$ & 10 & 10 & 10 & 8 & 7 & 5 & 5 & 6 \\
\hline 3 & $0,4-0,6$ & 0 & 0 & 0 & 0 & 0 & 0 & 0 & 0 \\
\hline 4 & $0,6-0,8$ & 0 & 0 & 0 & 0 & 0 & 0 & 0 & 0 \\
\hline 5 & $>0,8$ & 0 & 0 & 0 & 0 & 0 & 0 & 0 & 0 \\
\hline \multicolumn{2}{|c|}{ Tổng xã bị ảnh hưởng } & 41 & 40 & 40 & 35 & 33 & 33 & 33 & 33 \\
\hline \multicolumn{2}{|c|}{ Tổng số xã nghiên cứu } & \multicolumn{8}{|c|}{120} \\
\hline
\end{tabular}

Hình 2 thể hiện rõ cấp độ RR của các xã trong phạm vi nghiên cứu. Bản đồ RR cũng đã chỉ ra trong phạm vi nghiên cứu, một số xã có RR ở cấp 0 (không chịu RR). Mặc dù theo kết quả đánh giá hiểm họa các xã này đều có khả năng chịu ảnh hưởng của XNM với độ mặn trên $4 \%$. Tuy nhiên theo kết quả đánh giá về tính nhạy $(\mathrm{S})$ và độ phơi bày $(\mathrm{E})$, thì khả năng tác động $(\mathrm{S}+\mathrm{E})$ của $\mathrm{XNM}$ đến các xã đó nằm trong khoảng giá trị $0,42-0,76$ (với thang điểm từ 0 là không bị ảnh hưởng, đến 1 là ảnh hưởng rất lớn). Mặt khác, xét về khả năng ứng phó 
và khắc phục $(\mathrm{A})$ khi XNM xảy ra, giá trị $\mathrm{A}$ tại các xã nằm trong khoảng $0,6-0,75$ (với 0 là khả năng ứng phó và phục hồi kém và 1 là khả năng ứng phó và phục hồi rất tốt). Chính bởi vậy, theo định nghĩa của TDBTT, thì mức độ chịu tổn thương tại các xã này sẽ gần như bằng 0 . Khi đó, trên cơ sở phân tích các $\mathrm{KB} X N \mathrm{XN}$, các xã trên sẽ có cấp độ RR do XNM xấp xỉ bằng 0 tương ứng.

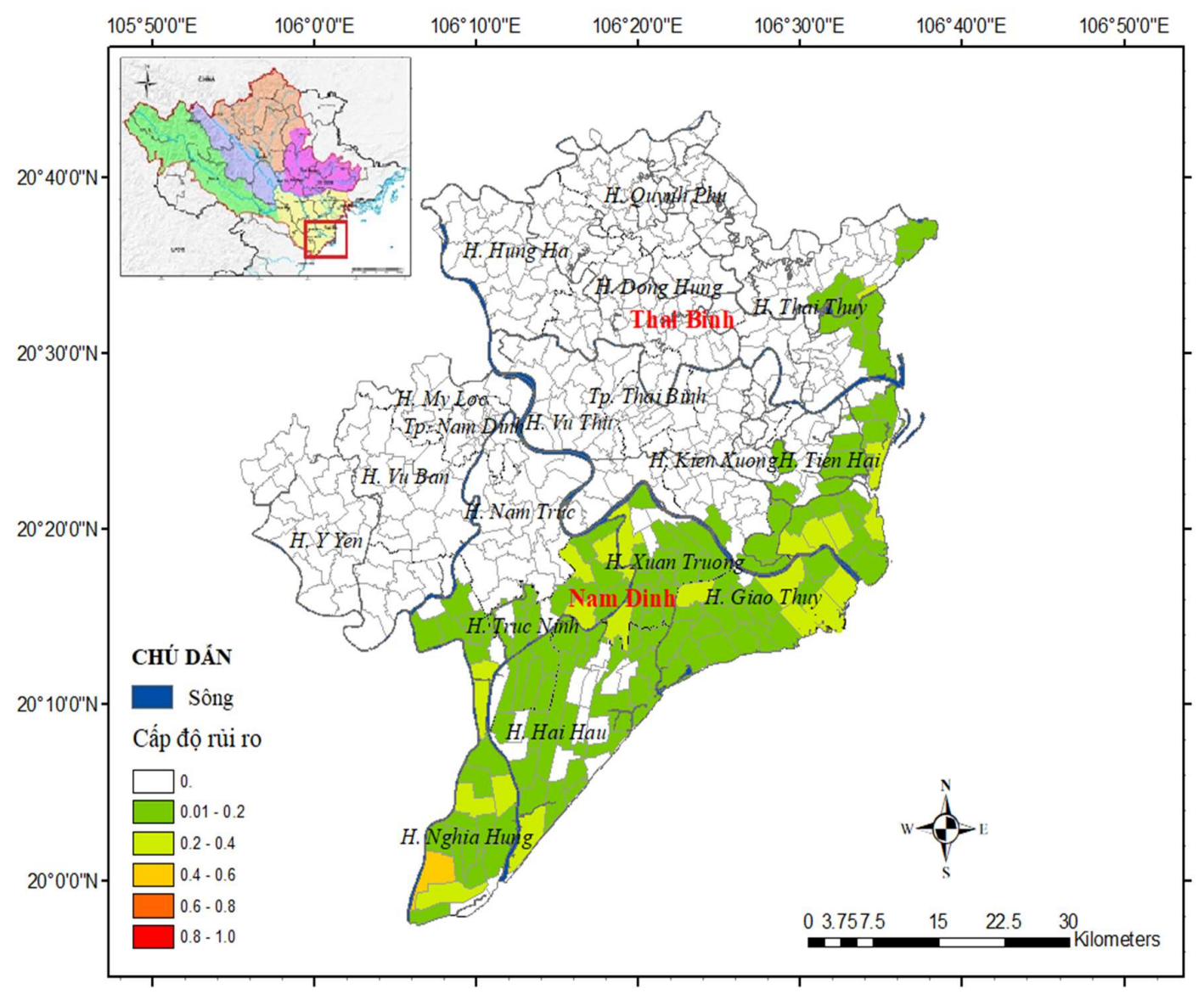

Hình 2. Bản đồ RR do xâm nhập mặn trên khu vực nghiên cứu.

\subsection{Kết quả tính toán theo các KB NBD}

So với $\mathrm{KB}$ nền, trong các $\mathrm{KB}$ NBD tổng số các xã bị tổn thương trên địa bàn tỉnh Nam Định có xu hướng tăng theo các cấp, cấp 1: từ 61 lên 67 xã, cấp 2: từ 7 lên 12 xã. Tổng số các xã bị tổn thương tăng từ 69 lên 80 xã. Trong khi đó, trên địa bàn tỉnh Thái Bình, gần như không có biến động về cấp độ tổn thương, số các xã chịu tác động chỉ dao động khoảng 31 xã. Cũng trong nhóm các $\mathrm{KB}$ này, số xã chịu tác động ở cấp độ 1 vẫn chiếm tỷ lệ cao, từ $77-$ $88 \%$. Các kết quả thể hiện trong Bảng 5 và Bảng 6 .

Các bản đồ ở Hình 3a-3e thể hiện sự phân bố cấp độ chịu tổn thương tại các xã theo KB nền và các KB NBD năm 2030, 2040, 2050a và 2050b. Trên các bản đồ cho thấy, trong phạm vi tỉnh Nam Định các xã Xuân Trung, Xuân Hồng (huyện Xuân Trường), Trung Đông, Phương Đình, Liêm Hải (huyện Trực Ninh), Hải Xuân, Hải Phong (huyện Hải Hậu) là các xã không bị tổn thương do XNM trong KB nền. Tuy nhiên, dưới tác động của NBD các xã này sẽ chịu tổn thương ở cấp độ 1 trong hầu hết các $K B$, riêng xã Xuân Hồng mức tổn thương sẽ tăng lên cấp 2 trong các KB 2040, 2050a và 2050b. Cùng với đó, các xã Giao Lạc, Giao Tiến (huyện Giao Thủy), Nam Điền, Nghĩa Hùng (huyện Nghĩa Hưng) tăng từ cấp độ 1 ở $\mathrm{KB}$ nền lên cấp độ 2 trong các KB NBD. 
Bảng 5. Số xã chịu tổn thương theo các KB NBD trên phạm vi tỉnh Nam Định.

\begin{tabular}{|c|c|c|c|c|c|c|}
\hline \multirow{2}{*}{ Cấp độ } & \multirow{2}{*}{ Khoảng giá trị } & \multicolumn{5}{|c|}{ Số xã bị tổn thương (V) theo các KB NBD } \\
\hline & & KB Nền & NBD 2030 & NBD 2040 & NBD 2050a & NBD 2050b \\
\hline 0 & $<0,01$ & 54 & 47 & 45 & 43 & 43 \\
\hline 1 & $0,01-0,2$ & 61 & 64 & 66 & 67 & 67 \\
\hline 2 & $0,2-0,4$ & 7 & 11 & 11 & 12 & 12 \\
\hline 3 & $0,4-0,6$ & 1 & 1 & 1 & 1 & 1 \\
\hline 4 & $0,6-0,8$ & 0 & 0 & 0 & 0 & 0 \\
\hline 5 & $>0,8$ & 0 & 0 & 0 & 0 & 0 \\
\hline \multicolumn{2}{|c|}{ Tổng số bị ảnh hưởng } & 69 & 76 & 78 & 80 & 80 \\
\hline \multicolumn{2}{|c|}{ Tổng số xã } & & & 123 & & \\
\hline
\end{tabular}

Bảng 6. Số xã chịu tổn thương theo các KB NBD trên phạm vi tỉnh Thái Bình.

\begin{tabular}{|c|c|c|c|c|c|c|}
\hline \multirow{2}{*}{ Cấp độ } & \multirow{2}{*}{$\begin{array}{c}\text { Khoảng giá } \\
\text { trị }\end{array}$} & \multicolumn{5}{|c|}{ Số xã bị tổn thương (V) theo các KB NBD } \\
\hline & & KB Nền & NBD 2030 & NBD 2040 & NBD 2050a & NBD 2050b \\
\hline 0 & $<0,01$ & 90 & 90 & 89 & 89 & 89 \\
\hline 1 & $0,01-0,2$ & 24 & 24 & 24 & 24 & 24 \\
\hline 2 & $0,2-0,4$ & 6 & 6 & 7 & 7 & 7 \\
\hline 3 & $0,4-0,6$ & 0 & 0 & 0 & 0 & 0 \\
\hline 4 & $0,6-0,8$ & 0 & 0 & 0 & 0 & 0 \\
\hline 5 & $>0,8$ & 0 & 0 & 0 & 0 & 0 \\
\hline \multicolumn{2}{|c|}{ Tổng xã bị ảnh hưởng } & 30 & 30 & 31 & 31 & 31 \\
\hline \multicolumn{2}{|c|}{ Tổng số xã nghiên cứu } & & & 120 & & \\
\hline
\end{tabular}

Đối với tỉnh Thái Bình, sự biến động về số xã chịu tổn thương cũng như tăng cấp do ảnh hưởng của NBD là rất nhỏ. Duy chỉ gia tăng thêm 1 xã (xã Thái Đô, huyện Thái Thụy) chịu tổn thương ở cấp 1 và 1 xã (xã Nam Thịnh, huyện Tiền Hải) tăng từ cấp 1 lên cấp 2 ở KB NBD 2040,2050a và 2050b. Xét về phạm vi toàn tỉnh thì số lượng không đáng kể, nhưng xét riêng với các xã Thái Đô và Nam Thịnh thì đó là điểm cần lưu ý để tăng cường khả năng ứng phó và khắc phục, giảm nhẹ tác động của XNM trong bối cảnh NBD.

\section{Kết luận}

XNM xảy ra thường xuyên ở các tỉnh thuộc đồng bằng ven biển sông Hồng-Thái Bình, đặc biệt là vào mùa kiệt đối với khu vực vực nghiên cứu là các huyện ven biển tỉnh Nam Định và Thái Bình. Kết quả đã chứng minh mức độ tác động của XNM đến cấp độ không gian là các xã thuộc khu vực nghiên cứu. Đã xây dựng bộ chỉ số gồm 27 biến nhằm xác định TDBTT cho 243 xã và từ đó phân tích ĐGRR cho các xã. Việc xây dựng bộ chỉ số và các biến dựa trên cơ sở phân tích điều kiện thu thập tài liệu, đảm bảo mối quan chặt chẽ giữa hiểm họa XNM với các đối tượng có khả năng bị tổn thương và các hoạt động nhằm ứng phó, khắc phục hiểm họa. Thông qua quá trình điều tra, phỏng vấn và xin ý kiến chuyên gia, bộ chỉ số đã được áp dụng để đánh giá TDBTT và phân tích $\mathrm{RR}$ cho các KB tần suất triều và KB NBD.

Kết quả cho thấy, trong nhóm KB tần suất triều $(25 \%, 20 \%, 15 \%, 10 \%, 5 \%, 3 \%$ và $1 \%)$, tổng số xã chịu tổn thương dao động trong khoảng từ 125-149 xã. Đối với nhóm KB NBD (KB nền, NBD 2030, 2040, 2050a và 2050b) số các xã chịu tổn thương tăng từ 99-111. Trong cả hai nhóm KB thì tổng số xã chịu tổn thương thuộc tỉnh Nam Định cao hơn từ 2 đến 3 lần so với tỉnh Thái Bình, xuất phát từ cấp độ hiểm họa do XNM tại tỉnh Nam Định cũng cao hơn. Với 5 cấp tổn thương và $R R$, tuy nhiên đa phần các xã trong khu vực nghiên cứu đều chịu tổn thương và RR ở cấp 1-2. Cùng với đó, cũng có thể nhận thấy một số xã trong phạm vi nghiên cứu mặc dù có hiểm họa XNM với độ mặn trên 4\%o, nhưng do các hoạt động về ứng phó và khắc phục kịp thời nên cấp độ tổn thương ở cấp độ rất thấp hoặc gần như không chịu tác động do XNM gây ra. 
Có thể nhận thấy việc đánh giá TDBTT và RR khi thực hiện ở phạm vi càng nhỏ, càng chi tiết thì càng làm rõ được những tác động do XNM gây ra cho từng khu vực cụ thể, đồng thời cũng chỉ ra được những ưu điểm và hạn chế của khu vực trong công tác ứng phó, khắc phục thiên tai. Điều đó sẽ hỗ trợ cho nhà quản lý, ra quyết định xây dựng các kế hoạch, phương án nâng cao năng lực ứng phó, khắc phục để giảm thiểu những tác động do thiên tai nói chung và XNM nói riêng.
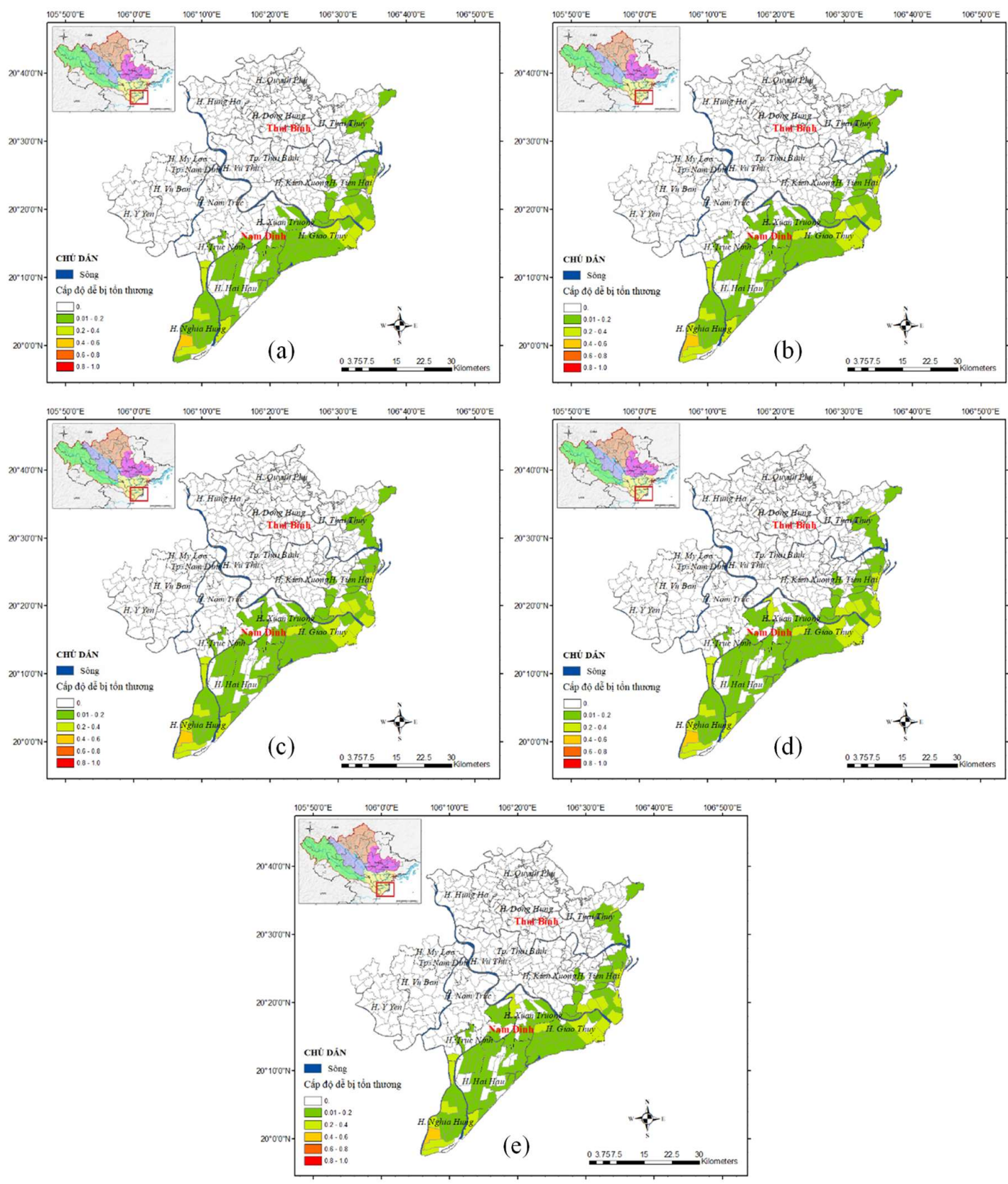

Hình 3. Bản đồ dễ bị tổn thương do XNM theo các KB NBD trên khu vực nghiên cứu: $\mathrm{a}) \mathrm{KB}$ nền, b) KB 2030, c) KB 2040, d) KB 2050a và e) KB 2050b.

Đóng góp của tác giả: Xây dựng ý tưởng nghiên cứu: N.M.Đ., T.H.T., N.V.Đ.; Lựa chọn phương pháp nghiên cứu: N.M.Đ., V.T.T.; Xử lý số liệu: N.V.Đ., V.T.T.; Xây dựng bộ chỉ số tính dễ bị tổn thương: N.V.Đ., V.T.T.; Phân tích kết quả: V.T.T., N.V.Đ., N.M.Đ.; Viết bản thảo bài báo: N.V.Đ., V.T.T., T.M.D.; Chỉnh sửa bài báo: N.M.Đ., V.T.T., T.H.T. 
Lời cám ơn: Tập thể tác giả xin trân trọng cảm ơn Sở NN và PTNT, Chi cục Thuỷ lợi, Đài KTTV các tỉnh Nam Định và Thái Bình; Phòng NN và PTNT, Phòng Tài nguyên \& Môi trường và UBND các xã thuộc huyện Nghĩa Hưng, Hải Hậu, Giao Thủy, Xuân Trường, Trực Ninh, Tiền Hải, Kiến Xương, và Thái Thụy; các Công ty TNHH MTV Khai thác công trình thủy lợi Nam Thái Bình, Bắc Thái Bình, Nghĩa Hưng, Hải Hậu, Xuân Thủy đã cung cấp tài liệu, tham gia phỏng vấn, và đóng góp ý để hoàn thành nghiên cứu này.

Lời cam đoan: Tập thể tác giả cam đoan bài báo này là công trình nghiên cứu của tập thể tác giả, chưa được công bố, không được sao chép từ những nghiên cứu trước đây; không có sự tranh chấp lợi ích trong nhóm tác giả.

\section{Tài liệu tham khảo}

1. UN Office for the Coordination of Humanitarian Affairs (UNOCHA). OCHA and Slowonset Emergencies. OCHA Occasional Policy Briefing Series, Brief No. 6, 2011.

2. Siegele, L. Loss and Damage: The theme of slow onset impact. Loss and Damage in Vulnerable Countries Initiative. 2012, pp. 20. Online available: http://www.lossanddamage.net/download/6532.pdf,

3. United Nations Framework Convention on Climate Change (UNFCCC). Slow onset events, 2012, pp. 61.

4. Stabinsky, D.; Hoffmaister, J.P. Loss and Damage: Defining Slow Onset Events. Third World Network, Briefing Paper on Loss and Damage No. 3, 2012, 1-7.

5. Junkes, M.B.; Tereso, A.P.; Afonso, P.S.L.P. The Importance of Risk Assessment in the Context of Investment Project Management: A Case Study. Procedia Comput. Sci. 2015, 64, 902-910. doi: 10.1016/j.procs.2015.08.606.

6. Preston, B.; Yuen, E.; Westaway, R. Putting vulnerability to climate change on the map: a review of approaches, benefits, and risks. Sustain. Sci. 2011, 6, 177-202.

7. Rosas, C.; Ocampo, L.; Gaxiola, G.; Sánchez, A.; Soto, L.A. Effect of Salinity on Survival, Growth, and Oxygen Consumption of Postlarvae (PL10-PL21) of Litopenaeus setiferus. J. Crustac. Biol. 1999, 19(2), 244-251.

8. Chen, J.C.; Lai, S.H. Effects of temperature and salinity on oxygen consumption and ammonia-N excretion of juvenile Penaeus japonicus Bate. J. Exp. Mar. Bio. Ecol. 1993, 165(2), 161-170.

9. Khương, N.Q.; Khanh, C.N.N.; Hưng, N.N. Ảnh hưởng của độ mặn nước tưới đến sinh trưởng, năng suất và sự sản sinh Proline của các giống lúa (Oryza sativa L.) trồng trên đất nhiễm mặn trong điều kiện nhà lưới. Tạp chí Khoa hoc Nông nghiệp Việt Nam 2018, 16(7), 671-681.

10. Taufiq, A.; Wijanarko, A.; Kristiono, A. Effect of amelioration on growth and yield of two groundnut varieties on saline soil. J. Degrad. Min. Lands Manag. 2016, 3(4), 639-647. https://doi.org/10.15243/jdmlm.2016.034.639.

11. Alam, M.Z.; Stuchbury, T.; Naylor, R.E.L.; Rashid, M.A. Effect of Salinity on Growth of Some Modern Rice Cultivars. J. Agron. 2004, 3, 1-10. https://doi.org/10.3923/ja.2004.1.10.

12. Bé, N.V.; Hằng, T.T.L.; Triển, T.V.; Trí, V.P.Đ. Ảnh Hưởng Của Xâm Nhập Mặn Đến Sản Xuất Nông Nghiệp, Thủy Sản Huyện Trần Đề, Tỉnh Sóc Trăng. Tạp chi Khoa học Truờng Đại học Cần Tho 2017, 6, 94-100.

13. Phương, L.N.; Sơn, D.H.; Đông, N.M. Đánh giá tiềm năng chịu mặn của cây đậu nành (Glycine max L.) và cây điên điển (Sesbania rostrata). Tạp chí Khoa học Công nghệ Nông nghiệp Việt Nam 2018, 3(88), 68-71.

14. Diệp, Đ.X.; Hương, Đ.T.T.; Phương, N.T. Ảnh hưởng của độ mặn lên sử dụng thức ăn và tiêu hao oxy cơ sở của tôm sú (Penaeus Monodon). Tạp chí Khoa hoc Trương Đại học Cần Tho 2010, 14, 135-145.

15. Sáng, V.V.; Mưu, T.T. Ảnh hưởng của nhiệt độ và độ mặn đến sự phát triển phôi của 
cá Song hổ (Epinephelus fuscoguttatus). Tạo Chí Khoa học và Phát triển 2013, 11(1), 41-45.

16. Toán, L.M.; Sáng, V.V.; Khuyến, T.Đ. Ảnh hưởng độ mặn đến khả năng sinh sản của cá rô phi vằn chọn giống trong môi trường lợ mặn (Oreochromis niloticusS). Tạp Chí Khoa hoc và Phát triển 2012, 10(7), 993-999.

17. Thảo, N.T.T. Ảnh hưởng của việc giảm độ mặn đến sinh trưởng và tỷ lệ sống của hàu (Crassotrea $\mathrm{SP}$ ) và tôm chân trắng (Penaeus Vannamei) trong hệ thống nuôi kết hợp. Tạp chí Khoa hoc Trưòng Đaị học Cần Tho 2011, 19, 211-221.

18. Văn, N.C.; Tuấn, N.L.; Anh, N.T.; Hiếu, P.V. Đánh giá tính dễ bị tổn thương và khả năng thích ứng do xâm nhập mặn đối với sản xuất nông nghiệp trong bối cảnh biến đổi khí hậu tại khu vực cửa sông ven biển tỉnh Nam Định. Tạp chi Khi tương Thủy văn 2020, 716, 63-78. doi: 10.36335/vnjhm.2020(716).63-78.

19. Thắng, Đ.Đ.; Thái, T.H.; Hòa, V.V. Đánh giá tính tổn thương cho cây lúa do xâm nhập mặn trên địa bàn tỉnh Thái Bình. Tạp chi Khí tương Thủy văn 2019, 698, 1121.

20. Đào, N.V.; Tú, V.T.; Thái, T.H.; Đăng, N.M. Nghiên cứu xây dựng bản đồ hiểm họa xâm nhập mặn vùng đồng bằng ven biển Nam Định và Thái Bình. Tạp chí Khí tượng Thüy văn 2021, 728, 93-106.

21. Ủy Ban Nhân Dân Tỉnh Nam Định. Kế hoạch phòng, chông thiên tai và tìm kiêm cứu nạn tỉnh giai đoạn 2021-2026, 2020.

22. Ủy Ban Nhân Dân Tỉnh Thái Bình. Kế hoạch Phòng chống thiên tai tỉnh Thái Bình giai đoạn 2021-2026, 2021. Online available: https://thuvienphapluat.vn/vanban/Tai-nguyen-Moi-truong/Ke-hoach-20-KH-UBND-2021-phong-chongthien-tai-tinh-Thai-Binh-2021-2026-470710.aspx.

23. Aref, F. Effect of saline irrigation water on yield and yield components of rice (Oryza sativa L.). African J. Biotechnol. 2013, 12(22), 3503-3513.

24. Siddique, A.B.; Islam, M.R.; Hoque, M.A.; Hasan, M.M.; Rahman, M.T.; Uddin, M.M. Mitigation of Salt Stress by Foliar Application of Proline in Rice. Univers. J. Agric. Res. 2015, 3(3), 81-88. https://doi.org/10.13189/ujar.2015.030303.

25. Liên, Q.T.A.; Thành, V.C.; Nhung, N.T.H. Đánh giá khả năng chịu mặn và phẩm chất của giống lúa Sỏi, Một Bụi Hồng và Nàng Quớt Biển. Tạp chí Khoa học Truờng Đại hoc Cần Tho 2012, 24a, 281-289.

26. Lam, N.H. Tương quan giữa độ mặn đất và các đặc điểm nông sinh học của một số giống lúa chịu mặn. Tạp chi Khoa học Trường Đại học Cần Tho 2018, 54(3), 75-83. https://doi.org/10.22144/ctu.jvn.2018.042.

27. Phi, N.Q. Úng dụng mô hình AquaCrop đánh giá ảnh hưởng của xâm nhập mặn đến năng suất lúa tại huyện Long Phú tỉnh Sóc Trăng. Tạp chí Tài nguyên nước 2017, 4, 58-62.

28. Quí, N.V.; Cường, N.M.; Giang, N.H.; Khanh, T.H., Gương, V.T. Mô phỏng cân bằng nước và muối cho cây bắp (Zea MaysL.) trên đất nhiễm mặn tại huyện Thạnh Phú - tỉnh Bến Tre. Tạp chi Khoa học Trường Đại Học Cần tho 2014, 35, 9-22.

29. Thắng, V.N.; Lãm, N.N.; Tuấn, T.A.; Quất, N.N.; Châm, L.T.T. Ảnh hưởng của mặn đến khả năng nảy mầm, sinh trưởng và năng suất của hai giống lạc L14 và L27. Tạp chi Khoa học Truờng Đại học Cần Tho 2017, 53(3), 123-133. https://doi.org/10.22144/ctu.jvn.2017.165.

30. Hải, N.T.T.; Khuynh, B.T.; Sửu, B.X.; Chính, V.Đ.; Phíp, N.T.; Hoàng, Đ.T. Phản ứng của một số giống lạc với điều kiện mặn nhân tạo. Tạp chi Khoa hocc và Phát triển 2013, 11(3), 269-277.

31. Tiến, N.V.Đ.; Sinh, V.N. Đất nhiễm mặn và Phương pháp sử dụng, 2016. Online available: https://ahrd.com.vn/News/Detail/76.

32. Kiểm, N.V.; Phước, T.V. Ẩnh hưởng của độ mặn đến sinh trưởng, tỷ lệ sống và biến 
đổi áp suất thẩm thấu cá sặc rằn (Trichgaster pectoralis). Tạp chi Khoa học Truờng Đai hoc Cần Tho 2011, 19b, 219-224.

33. Việt, L.Q.; Hải, T.N.; Tuấn, N.A. Ảnh hưởng của độ mặn lên tăng trưởng và tỷ lệ sống của cá đối giống (Liza subviridis) giai đoạn 1 đến 3 tháng tuổi. Tạp chí Khoa hoc Trường Đại học Cần Tho 2010, 14, 205-212.

34. Đàn, T.V.; Điều, V. Nghiên cứu khả năng thích ứng độ mặn của cá nâu (Scatophagus Argus) trong điều kiện biến đổi khí hậu ở tỉnh Thừa Thiên Huế. January 2014, 1-8. Online available: https://www.researchgate.net/publication/274889301.

35. Xuyến, B.T.K. Khả năng thích nghi độ mặn của cá Basa. Tạp chi Khoa hoc Truờng Đại hoc An Giang 2015, 7(3), 37-44.

36. Hường, H.K.; Sơn, L.P.; Việt, L.Q.; Hương, Đ.T.T.; Hải, T.N. Ảnh hưởng độ mặn lên chu kỳ lột xác, sinh sản và tăng trưởng của tôm càng xanh (Macrobrachium rosenbergii). Tạp chí Khoa họ Truòng Đại hoc Cần Tho 2015, 38, 35-43. https://doi.org/10.13140/RG.2.2.19676.85121.

37. Tới, H.T.; Vân, N.T.H. Ảnh hưởng sốc độ mặn trong giai đoạn thả giống lên sinh trưởng của tôm sú (Penaeus monodon) ương theo công nghệ Biofloc. Tạp chí Khoa học Nông nghiệp Việt Nam 2018, 16(2), 132-140.

38. Bá, Đ.T. Giải pháp nuôi và ương cá nước ngọt mùa hạn mặn. Thủy sản Việt Nam, 2020.

39. Phương, N.P.H. Biện pháp hạn chế tác hại của hạn mặn đến đàn vật nuôi. Trung tâm Khuyến nông Quốc gia, 2013.

40. Dolan, A.H.; Walker, I.J. Understanding vulnerability of coastal communities to climate change related risks. J. Coast. Res. 2006, 3(SI 39), 1316-1323.

41. Dwyer, A.; Zoppou, C.; Nielsen, O.; Day, S.; Robert, S. Quantifying social vunerability: a methodology for indentifying those at risk to natural hazards, 2004.

42. ABARE-BRS. Indicators of community vulnerability and adaptive capacity across the Murray-Darling Basin: A focus on irrigation in agriculture. ABARE-BRS Client Rep. 2010, 43099, 1-68.

43. Vu, T.T.; Ranzi, R. Flood risk assessment and coping capacity of floods in central Vietnam. J. Hydro-Environment Res. 2017, 14, 44-60. https://doi.org/10.1016/j.jher.2016.06.001.

\title{
Risk Assessment due to Salinity Intrusion in Coastal Plains of Nam Dinh and Thai Binh
}

\author{
Nguyen Van Dao', Vu Thanh $\mathrm{Tu}^{2}$, Tran Hong Thai ${ }^{3}$, Nguyen Mai Dang ${ }^{2,4^{*}}$ \\ ${ }^{1}$ Federation of Hydrometeorological Surveys, Vietnam Meteorological and Hydrological \\ Administration; daotvmt@gmail.com \\ ${ }^{2}$ Faculty of Water Resources Engineering, Thuyloi University; vutu@tlu.edu.vn \\ ${ }^{3}$ Vietnam Meteorological and Hydrological Administration; tranthai.vkttv@gmail.com \\ ${ }^{4}$ Center for Internation Education, Thuyloi University; dang@tlu.edu.vn
}

Abstract: Saltwater intrusion occurs frequently causing impacts on socio-economic development activities. In order to clarify the impacts of saltwater intrusion on coastal areas of Nam Dinh and Thai Binh province, a set of indicators for vulnerability assessment is developed to assess the risks and losses due to salinity. The set of vulnerability assessment indicators involves 27 variables with weighting factors applied for sensitivity analysis, exposure, and adaptive capacity for 243 communes in the study. Methods such as investigation, local people and experts' interview, and statistical analyses are applied to determine the values of the variables and standardized for analyzing vulnerability and risk. The results show that the number of communes affected is from 125 to 149 in the scenario 
group of tidal frequency, and from 99 to 111 in the scenario group of sea level rise. It is noted that more than $80 \%$ of the communes in the study area of Nam Dinh were affected. Five levels of vulnerability and risk are analyzed, most of the communes are at levels 1 and 2. The results have shown that, although in some communes the level of hazard is quite high, with good coping capacity, the level of risk may be very low or may not occur.

Keywords: Salinity; Index; Vulnerability; Risk; Sea level rise. 